\title{
I. Afroindigenismo por Escrito na Amazônia
}

\author{
Afroindigenismo Por Escrito en el Amazonía
}

Afroindigenismo for Written in the Amazon

Agenor Sarraf Pacheco ${ }^{1}$

\begin{abstract}
Resumo
Tomando por base a produção literária da poetisa e romancista marajoara Sylvia Helena Tocantins, cruzando com a historiografia brasileira e amazônica sob a perspectiva teórica dos Estudos Pós-Coloniais e Decoloniais, o texto analisa circuitos da presença indígenas, africana e afroindígena na Amazônia Marajoara nas últimas décadas e em exemplificações com os tempos coloniais. Nessas zonas de contato, desvendam-se saberes, fazeres, crenças, costumes, tradições e formas de luta de populações de tradições orais historicamente invisibilizadas ou esteriotipadas pelo poder das escritas colonialistas. Ciente das especificidades e fronteiras porosas existentes entre os campos da literatura e da história, a comunicação procura cotejada e cruzar a narrativa literária com outras narrativas de cronistas, viajantes, historiadores e antropólogos para apreender sinais da história e cultura indígena, africana e afroindígena na região. Nesses escritos, acompanham-se experiências de homens e mulheres de matrizes indígenas e africanas que se esparramaram, apropriaram-se, ressignificaram e compartilharam afeto e táticas para driblar a colonialidade de seus corpos, cosmovisões e sentidos. Deste modo, entre os tempos coloniais e os tempos contemporâneos, histórias, trajetórias e imaginários das culturas indígenas e africanas persistiram, resistiram, sofreram baixas e reinventaram-se nas fronteiras amazônicas. Finalmente, as informações reunidas e trabalhadas acerca da vida e obra de Sylvia Helena Tocantins, em simbiose com diferentes outras escritas, permitiram exercitar práticas de "desobediência epistêmica" para captar o afroindigenismo como postura criativa e problematizadora de essencialismos étnicos que, muitas vezes, negam a interculturalidade dos encontros culturais em territórios da diferença colonial.
\end{abstract}

Palavras-Chaves: Afroindigenismo; Literatura; Zonas de Contato; Amazônia Marajoara

\section{Resumen}

Basado en la literatura de la poeta y novelista marajoara Sylvia Helena Tocantins, el cruce con la historiografía brasileña y amazónica desde la perspectiva teórica de Post-colonial y estudios descoloniales, el documento analiza circuitos de presencia indígena, africana y afroindígena Amazon Marajoara en el pasado décadas y en ejemplificaciones con tiempos de la colonia. En estas zonas de contacto, están en el conocimiento revelado, obras, creencias, costumbres, tradiciones y formas de lucha de los pueblos de tradiciones orales hechas históricamente invisible o estereotipados por el poder de los colonialistas escritos. Consciente de las especificidades y la porosidad de las fronteras entre los campos de la literatura y la historia existente, la comunicación intenta cotejar y cruzar la narrativa literaria con otros relatos de cronistas, viajeros, historiadores y antropólogos para aprehender signos de la historia y la cultura indígena, africana y afroindígena en la región. Estos escritos se acompañan de experiencias de hombres y mujeres de raíces indígenas y africanas que se propagan, si fuera apropiado, ressignificaram y compartido afecto y tácticas para eludir la colonialidad de su cuerpo, los sentidos y visiones del mundo. De este modo, entre los tiempos de la colonia y la época contemporánea, historias y trayectorias imaginarias de las culturas indígenas y africanos presentan aún resistían sufrido bajas y reinventarse a sí mismos en las fronteras del Amazonas. Por último, la información recopilada y trabajó sobre la vida y obra de Sylvia Helena Tocantins, en simbiosis con varios otros escritos, prácticas de trabajo habilitados "desobediencia epistémica" para capturar la afroindigenismo como la posición creativa y el problema del esencialismo étnico que a menudo niegan interculturalidad de los encuentros culturales en los territorios de la diferencia colonial.

Palabras claves: Afroindigenismo; literatura; Zonas de contacto; Amazon Marajoara

\footnotetext{
${ }^{1}$ Pós-Doutor em Comunicação, Linguagens e Cultura (UNAMA, 2016). Mestre e Doutor em História Social (PUC-SP, 2004/2009). Professor do Curso de Museologia e dos Programas de Pós-Graduação em Antropologia e História Social da Amazônia da Universidade Federal do Pará (UFPA) - agenorsarraf@ uol.com.br
} 


\begin{abstract}
Based on the literary production of Marajoara poetess and novelist Sylvia Helena Tocantins, which crosses Brazilian and Amazonian historiography under the theoretical perspective of Postcolonial and Decolonial Studies, the text analyzes the circuits of the indigenous, African and Afroindigenous presence in the last Marajoara Amazon Decades and in exemplifications with colonial times. In these areas of contact, knowledge, beliefs, customs, traditions and forms of struggle of populations of oral traditions historically invisibilized or stereotyped by the power of colonialist writings are unveiled. Aware of the specificities and porous boundaries between the fields of literature and history, communication seeks to cross-check the literary narrative with other narratives of chroniclers, travelers, historians and anthropologists to seize signs of the history, culture and Afroindigenous in the region. These writings are accompanied by the experiences of men and women from indigenous and African matrices who have spread, appropriated, resignified and shared affection and tactics to circumvent the coloniality of their bodies, worldviews and senses. Thus, between colonial times and contemporary times, histories, trajectories and imaginaries of indigenous and African cultures persisted, resisted, suffered casualties and reinvented themselves on the Amazonian frontiers. Finally, the information gathered and worked on the life and work of Sylvia Helena Tocantins, in symbiosis with different writings, allowed to practice practices of "epistemic disobedience" to capture the afroindigenismo as a creative and problematizing posture of ethnic essentialisms that often deny The interculturality of cultural encounters in territories of colonial difference.
\end{abstract}

Keywords: Afroindigenismo; Literature; Contact Zones; Marajoara Amazon

\title{
1. Literatura e História em Circuitos Afroindígenas
}

(...) Tenho saudade das minhas cantigas marajoaras, empoleirada na lenha cortada, que tanto encantavam o boi estrela D’Alva e faziam a carroça rolar no ritmo da música. Quisera ter pleno domínio sobre as letras para transportar ao papel tudo que me viesse à imaginação, porém, nem assim conseguiria prestar-lhe o culto que você merece, pois tudo quanto dissesse ainda seria pouco (TOCANTINS, 1987, p. 1112).

Sylvia Helena Tocantins ${ }^{2}$, romancista, poetisa, contista e cronista, filha da aristocracia marajoara, apaixonada pelo pai, mas sensível aos saberes dos mundos indígenas e africanos $^{3}$ na Amazônia Marajoara, reconstitui nesse fragmento, códigos e linguagens de tradições orais e possibilita pensar a saudade do passado não apenas como tempo de perdas, mas especialmente como motivação à produção de escrituras que podem aproximar seus leitores de vivências silenciadas em narrativas convencionais e fazê-los mergulhar em outras histórias locais (HAMPATÉ BÂ, 2011).

Tomando por base a produção literária da poetisa e romancista marajoara Sylvia Helena Tocantins, cruzando com a historiografia brasileira e amazônica sob a perspectiva teórica dos Estudos Pós-Coloniais e Decoloniais, o texto analisa circuitos da presença indígenas, africana e afroindígena na Amazônia Marajoara nas últimas décadas e em

\footnotetext{
${ }^{2}$ Sílvia Helena Tocantins nasceu em 1933 e faleceu em 2016. Desde 1992 fez parte da Academia Paraense de Letras. Entre seus trabalhos publicados destacam-se Respingos de Maresia (Poesia), As Ruínas de Suruanã (Romance), No Tronco da Sapopema (Contos) e A Lenda do Amor Eterno (Romance).

${ }^{3}$ Os termos índio e negro, no contexto da colonialidade do poder, foram conforme Quijano citado por Mignolo, identidades forjadas para homogeneizar e apagar a diversidade das identidades "índia" e "negra" (MIGNOLO, 2003, p. 85).
} 
exemplificações com os tempos coloniais. Nesses quadros, como a maior fiandeira do passado, na tonalidade do pensamento de Tocantins, a recordação alinhava cenas e episódios com suas gentes, "tatuadas no ontem de cada um de nós". Deitada nessas memórias, assinalou a escritora: "Vejo-me ainda criança, correndo pelos campos dourados de sol, cabelos ao vento, subindo aterros e descendo rampas, ou dentro do mato buscando um ninho ou fruto, passeando de igarité pelos paranás, colhendo flor de mururé, deslumbrada com o canto e plumagem colorida das aves" (TOCANTINS, 1987, p. 11). A casa-grande de seus pais estava sempre repleta da presença e dos saberes de indígenas, negros e afroindígenas, sem esquecer as formas de escravidão, servidão e exploração da mão de obra nativa e diaspórica, as memórias de Helena Tocantins estão urdidas pelo afeto. O contato com estes filhos da floresta e do "Atlântico Negro" (GILROY, 2001), em suas diferentes linguagens, falada, corporal, rítmica, no tempo das férias escolares, fez a escritora as reter no universo de suas aprendizagens e lembranças de infância e adolescência, traduzindo-as em poesias, contos e romances, numa peleja contra o esquecimento de um "tempo foi", definidor de sua identidade "cabocla". É preciso lembrar, conforme assinala Gilroy (2001, p. 25), que "sob a chave da diáspora nós poderemos então ver não a raça, e sim formas geopolíticas e geoculturais de vida que são resultantes da interação entre sistemas comunicativos e contextos que elas não só incorporam, mas também modificam e transcendem". Igualmente que "a mistura não deve ser interpretada como perda de pureza, e sim como um princípio de crescimento que ajudou a formar o mundo moderno" (SANTOS, 2002, p. 275).

A escrita literária resguarda a magia de jogar e embaralhar tempos históricos, aparentemente difíceis de serem desembaraços, quando lida ao pé da letra. Se cotejada a outras informações, sem esquecer o chão e a trajetória de vida de quem a produziu ${ }^{4}$, permite alçar importantes voos e desvendar rostos, vozes, saberes, fazeres e cotidianos de povos quase sempre camuflados em outros gêneros textuais, especialmente narrativas oficiais. Nos versos que abrem este texto, Helena Tocantins traz negros da fazenda de seu pai, produtores, cantadores e tocadores de chulas. Homens e mulheres, filhos da diáspora africana que se esparramaram, apropriaram-se, ressignificaram e compartilharam e formaram uma rede de contatos e trocas culturais e experiências com indígenas, brancos pobres e elite senhorial nos

\footnotetext{
${ }^{4}$ Tornam-se frágeis e difíceis de contextualizações, argumentos históricos elaborados a partir do olhar literário sem entender o autor no seu tempo, sua percepção de vida e sociedade, os circuitos por onde caminhou, os enfrentamentos políticos e literários estabelecidos, enfim, seu projeto de vida frente à realidade cartografada, recriada e analisada. Seguindo essa direção, fiz esforços para inserir esse texto no bojo dessa orientação. Sobre essa questão, Cf. (ELEUTÉRIO, 2000, p. 235).
} 
campos marajoaras. Na esteira de Gilroy resenhado por Santos (2002, p. 273) é preciso pensar que

a formação dessa rede possibilitou às populações negras durante a diáspora africana formarem uma cultura que não pode ser identificada exclusivamente como caribenha, africana, americana, ou britânica, mas todas elas ao mesmo tempo. Tratase da cultura do Atlântico Negro, uma cultura que pelo seu caráter híbrido não se encontra circunscrita às fronteiras étnicas ou nacionais.

Tomando a Amazônia Marajoara como território de saberes e fazeres indígenas e da diáspora africana, emerge das memórias de Tocantins a cultura gastronômica em suas misturas. $\mathrm{O}$ açaí tomado na cuia pitinga ${ }^{5}$ que a tapuia amassava no alguidar de barro. $\mathrm{E}$ as artes da mestra de fogão, Jovelina, a mãe-preta, com seus beijus de tapioca e mandioca. $\mathrm{O}$ café torrado com erva-doce. A canjica, broinhas, mungunzás, pamonhas e cuscuz. O queijo de manteiga e a coalhada. Os refrescos de cupuaçu, muruci, taperebá, inajá, tucumã, bacuri. O pato no tucupi e as caranguejadas. $\mathrm{O}$ arroz com marreco, as moquecas, a galinha à cabidela, a carne de sol, os assados na brasa, peixadas, guisado de espinhaço de boi, as fritadas de camarão (TOCANTINS, 1998, p. 12).

Os escritos da literata permitem mergulhos tanto no cardápio alimentar do Marajó dos Campos, quanto no cotidiano vivido por populações de tradições orais, detentoras de saberes indígenas, africanos e afroindígenas em intensas simbioses com reinos animais, vegetais, minerais e humanos pelos ambientes anfíbios do grande arquipélago (ANTONACCI, 2001; 2005). Lembranças de infância compartilhadas por esta literata com a indígena Jandyra, criada sob os cuidados da avó paterna, "um pedaço de morena que enchia os olhos da vaqueirada", recompõem universos lúdicos construídos em cenários de águas 6 . "Nas horas de aguaceiro, ela corria a pular, batendo as pernas com uma ramagem fina. Comia peixe cru, tecia peneiras, cestos, fazia louça de barro" (TOCANTINS, 1998, p. 191-197). Sob os ralhos do pai e os conselhos da negra Jovelina, a menina Helena inspirava-se nas peraltices da indígena e com ela partilhava os mistérios e riquezas dos campos em tempos de chuvas.

Os textos de Sylvia Helena remontam às quatro primeiras décadas do século XX, quando o epistemicídio ${ }^{7}$ indígena já havia avançado poderosamente na região marajoara e, por

\footnotetext{
${ }^{5}$ Cuia com inscrições artesanais em forma de variados riscos.

${ }^{6}$ É recorrente, nos escritos de Sylvia Helena, a presença, as artes e os ensinamentos adquiridos com a indígena Jandyra Ela foi roubada ainda criança no Alto Tocantins e trazida para Marabá, onde foi dada como presente para a avó. Entre as páginas de suas narrativas, dedicou um conto específico para falar dessa personagem. (TOCANTINS, 1998, p. 191-197).

${ }^{7}$ A expressão foi formulada por Boaventura de Sousa Santos para quem "o genocídio que pontuou tantas vezes a expansão européia foi também um epistemicídio: eliminaram-se formas de conhecimento estranho porque eram sustentadas por práticas sociais e povos estranhos". [...] Esse processo "ocorreu sempre que se pretendeu
} 
isso, não existiam mais aldeias indígenas com suas tradicionais formas de organização social. Contudo, muitos nativos e seus descendentes, ainda compunham espaços de casas isoladas e distantes da cidade ou ambientes de vilas e fazendas, como se acompanha nos escritos de Helena Tocantins a respeito da história de Jandyra. Para o lado do Marajó dos Campos, o poder das fazendas com a exploração intensa da mão de obra africana contribuiu para a reprodução continua da presença negra e seus modos de vida, aspecto fortemente trabalhando pela literata. Essa teimosa presença que a historiografia mais clássica fez questão de negligenciar dos estudos amazônicos (PEREIRA, 1952; SALLES, 1973; VERGULINOHENRY \& FIGUEIREDO, 1990; BEZERRA NETO, 2001; GOMES, 2005), emerge no modernismo marajoara, costurando com "negros da terra", brancos, nordestinos e outros grupos humanos, uma rede de inextrincáveis relacionamentos afroindígenas.

Em entrevista com esta literata foi possível conhecer experiências e olhares de nordestinos migrantes sobre o mundo das águas marajoaras, no contexto da II Guerra Mundial. Helena Tocantins contou que seu pai, o fazendeiro piauiense Francisco Soares de Melo, no início dos anos de 1940, tomou conhecimento de que levas de nordestinos estavam vindo à Amazônia para trabalharem na região, especialmente nos seringais do Acre. Por ser nordestino, o fazendeiro resolveu dirigir-se à hospedaria Tapanã, local para onde eram encaminhados os retirantes, trazendo para sua propriedade seis famílias, cada uma com seis filhos ${ }^{8}$.

Quando atravessaram a baia de Marajó, essas famílias em diáspora ficaram impressionadas com a quantidade de águas ali reinantes. Segundo Tocantins, os três mil pés de coqueiros plantados por "negros, mulatos e mestiços", às margens do rio, nos limites daquela fazenda de seu pai, a quantidade e facilidade para capturar o peixe, o contato com uma paisagem completamente diversa do nordeste brasileiro, fizeram estas famílias de retirantes, chamarem a região de grande paraíso. As águas e toda riqueza que dela emana em contraste com o agreste e "faminto sertão", em tempo de seca, permitem a construção de outras imagens da presença nordestina na Amazônia. Das memórias da romancista não emergiram versões das possíveis dificuldades, conflitos e limites vividos por aquelas seis famílias no Marajó dos Campos. Reteve especialmente trocas culturais no universo do

subalternizar, subordinar, marginalizar, ou ilegalizar práticas e grupos sociais que podiam constituir uma ameaça à expansão capitalista. [...]" O esmagamento de saberes e fazeres de grupos indígenas e africanos "significou um empobrecimento irreversível do horizonte e das possibilidades de conhecimento", que a humanidade precisou operar em tempos futuros. (SANTOS, 2001, p. 328-9).

${ }^{8}$ Entrevista realizada com a romancista e poetisa, em abril de 2007, na sua residência. 
trabalho, alimentação, crenças, rituais, saberes, cantorias estabelecidas com nativos da região, filhos e descendentes da África Negra erradicados nas fazendas paternas.

Formado pela multiplicidade de rios, furos ou paranás; lagos quase sempre de denominações indígenas, como Paracauari, Anajibu, Atuá, Cajuuba, Arari, Parauau, Buiussu, Anajás, para citar alguns, o regime flúvio-marinho marajoara, desde os tempos de colonização, colocou a região em rotas e contatos entre si e com povos e culturas de Belém, Macapá, Caeina, atingindo portos antilhanos. Com as diásporas africanos iniciadas no Caribe, tais fluxos e refluxos possibilitaram a renovação de intercâmbios de costumes, crenças, tradições, ideias e ideais, assim como mercadorias, sons e ritmos da cultura material e sensível de diferentes grupos e etnias na formação do Atlântico Equatorial (CHAMBOULEYRON, 2006).

O emaranhado de rios que desenham percursos por dentro da floresta Amazônia, os quais ligam a Amazônia Marajoara a Belém, Macapá, fronteira com a Guiana Francesa, também foram espaços para entradas e fugas de africanos no Grão-Pará. Oriundos dos grupos bantus e sudaneses, nações de Angola, Congo, Bengueja, Bareua ou Barana, Bijagó, Cabinda, Carabá ou Calabar, Caçanje, Fulupe, Guiné, Lalor ou Lalu, Mina, Mandinga, Malhi, Macuá ou Macua, Moçambique, Pabana ou Babana (PEREIRA, 1952), espraiaram-se por todo arquipélago, fossem trabalhadores de fazendas, pescadores, agricultores, caçadores, ou ferreiros, carpinteiro, marceneiros, escultores, vivendo em mocambos e quilombos escondidos entre rios e florestas.

Pouco se sabe a respeito de tensões, conflitos e negociações destes encontros de nações africanas com grupos indígenas espalhados pela região e em que condições forjaram alianças, solidariedades, partilhando saberes e visões de mundo, especialmente em torno de suas liberdades. Entretanto, alguns estudiosos apresentam em suas pesquisas elementos para serem pensadas essas experiências sociais nos circuitos Pará/Macapá/Caiena, ao mesmo tempo em que outras investigações como as de Gandon (1997), Arruti (2001), Schwartz (2003), Goldman (2015) permitem vislumbrar a formação de zonas de contato afroindígena em muitas regiões do Brasil (PRATT, 1999).

O historiador Flávio Gomes assinalou que fugas e deserções de índios, negros, crioulos, mestiços, ocorridas entre os séculos XVIII e XIX da Guiana Francesa ao Pará, ou vice-versa, tiveram, como espaço principal, caminhos de águas que cercavam diferentes espaços escolhidos como táticas de esconderijos. "Saindo de Caiena em direção ao Pará ou vice-versa, via de regra, os fugitivos optavam pelo mar e/ou rios que banhavam a região. Enfrentar as escarpadas matas, nem pensar. Seriam presas fáceis da fome, de animais ferozes, 
das febres e dos cães farejadores dos seus capturadores franceses. (...) Era pela via fluvial, que estes desertores, construindo canoas e jangadas aventuraram-se" (GOMES, 1999, p. 242).

No contexto dessas fugas, mais precisamente em novembro de 1783, depois da expulsão dos jesuítas do Brasil, o naturalista Alexandre Rodrigues Ferreira, filósofo ilustrado, partiu de Belém para conhecer a grande ilha de Joanes ${ }^{9}$, sob o comando de 19 índios remeiros. Nesta viagem, a esperança transformou-se em susto pelo perigo que a canoa atravessou, dada a presença do "rijo vento, com trovoadas secas", rompendo uma das velas. Em seu escrito, o intelectual português redigiu que uma de suas maiores felicidades foi ter escapado das nove correntezas atravessadas (FERREIRA, 1964, p. 147).

As antigas aldeias marajoaras transformaram-se, após a expulsão jesuítica em vilas de denominações portuguesas, porém suas Igrejas preservaram os santos instalados pelos missionários. A povoação de Monforte cultuava N. Sra da Conceição; Monsarás, São Francisco; Salvaterra, N. Sr ${ }^{\mathrm{a}}$ da Conceição; Soure, Menino Jesus; Mondim, São José; Condeixa, N. Sr ${ }^{a}$ da Conceição; Vilar, São Francisco; Ponta de Pedras, N. Sr ${ }^{a}$ da Conceição; Cachoeira, N. Sr ${ }^{\mathrm{a}}$ da Conceição; Chaves, São Francisco (FERREIRA, 1964, p. 152) ${ }^{10}$. Rodrigues Ferreira ainda observou que as fazendas, na parte de campos, estavam situadas próximas a rios e todas elas munidas de capelas. Nestes espaços, "tapuios, pretos forros, mulatos, cafusos, caribocas, etc" (FERREIRA, 1964, p. 152) desenvolviam diferentes ofícios, sobressaindo a arte de remar por aquele arquipélago retalhado de rios em águas calmas e tenebrosas. "Tem eles a obrigação de, sendo chamados pelo seu comandante, aparecem sempre com o seu remo porque devem estar prontos para as diligências marítimas" (FERREIRA, 1964, p. 152).

É preciso focalizar de antemão que a especificidade da escravidão no Grão-Pará, com a "existência de uma agropecuária voltada para o mercado, estruturada na agricultura comercial, fazendas de gado" (BEZERRA NETO, 2001, p. 18), roças de farinha, matas com drogas-do-sertão, com características crioulas, interculturais, fundada em uma sociedade paternalista, diferenciou-se dos centros tradicionais da escravidão no Brasil (RICCI in BEZERRA NETO, 2001, p. 8), o que revelou experiências singulares nos processos de

\footnotetext{
${ }^{9}$ Primeiro nome do arquipélago, recorrente nos escritos coloniais. Duas versões explicam o surgimento desta denominação. A primeira teria sido dada por Vicente Yanez Pinzon. Este navegador por ter alcançado a ilha no dia de seu aniversário, a batizou com corruptela de seu sobrenome Yanez, que traduziu para Joanes. Para Rodrigues Ferreira, o nome surgiu em função de habitar a ilha a nação joanina. Durante o século XVIII é que vai surgir o nome Marajó, como uma tradução do termo indígena Mybarayo, cujo significado é barreira ou anteparo do mar. A partir daí, viajantes, escritores e autoridades utilizarão tanto um quanto o outro nome para se referir ao grande arquipélago.

${ }^{10}$ Algumas dessas vilas coloniais, depois foram transformadas em municípios e outras permaneceram apenas como povoações.
} 
ocupação portuguesa na Amazônia. Por estes termos, quando a retina do olhar investigativo se dilata para a disseminação do número de mestiços presentes em estatísticas populacionais e não fica restrita à pureza de uma cor negra ${ }^{11}$, a percepção dos Marajós Afroindígenas, na formação histórica e cultural amazônica, amplia-se.

Dos tempos coloniais para os tempos contemporâneos histórias, trajetórias, lutas, saberes, fazeres, crenças e imaginários das culturas indígenas e africanas persistiram, resistiram, sofreram baixas e reinventaram-se nas fronteiras amazônicas. Nos escritos de Sylvia Helena sobre o Marajó dos Campos, tais heranças são descritas de modo singular ${ }^{12}$. Inicialmente preferiu ver a região "dentro da grandiosidade paradisíaca presenteada pela natureza. Ambiente rude e agreste, mas pleno de encantamento". Seus comentários trazem a imagem de um marajoara acomodado "como canarana e o mururé que dormitam em cima d'água e só caminham quando a maré os leva". Sua leitura de mundo, a princípio, parece diferir a de Dalcídio Jurandir (1939) e Giovanni Gallo, este último procurando "desdobrar o direito e o avesso da ilha, suas misérias e riquezas", evidenciou seus problemas sociais. Tocantins ao ler Marajó: a ditadura da água, de padre Gallo (1981), o interpretou como uma espécie de grito de denúncia e defesa da cultura e das gentes marajoaras, "de um certo modo enterradas na lama, morando em palafitas". Mesmo sem assentar as bases de seu pensamento literário em torno dos contrastes da região, pode-se surpreender, em passagens de seus escritos, convergências com a escrita de Jurandir e padre Gallo. A assertiva torna-se visível, quando expressou consciência sobre a complexa vivência no Marajó dos Campos:

\begin{abstract}
Marajó é um contraste de riquezas e misérias. Junto as cercas das majestosas fazendas, vê-se casebre de barro com portas de japá ${ }^{13}$, banheiros de palha, igarités ${ }^{14}$ rústicas, balouçando nos igarapés, amarradas nos cipós de aninga, a beira dos barrancos. Mais além, sobre varais ou galhos, trapos estendidos e sobre jiraus, vasilhames de barro, cuias e colheres de pau. Ali um touro de raça, imponente roliço, racionado; aqui um cachorro magrelo e faminto, farejando as toiças na esperança de um calango. Tudo na mesma paisagem esmeraldina, sem horizontes (TOCANTINS, 1987, p. 14).
\end{abstract}

\footnotetext{
${ }^{11}$ Diferentes estudiosos têm procurado romper com as buscas pelo "essencialismo" quando se discute processos identitários em comunidades humanas. Essas identidades hoje são híbridas, mescladas, misturadas, compósitas, fundidas no corpo-a-corpo de infinitos contatos e relações. Entre estes estudiosos, ainda que em outro contexto, ver: (HALL, 2003).

${ }^{12} \mathrm{O}$ pensamento de Tocantins, como de qualquer escritor, literato, pesquisador é filho de seu tempo. A arte de talhar letras para compor poesias e prosas poéticas iniciou na década de 80, já com uma gama de experiência e leitura de outros universos. Ávida leitora dos clássicos da literatura nacional e internacional, em 1982, esta mulher paraense de fortes vivências nos campos marajoaras, despertou para o mundo dos versos, quando lançou seu primeiro livro de poesias Respingos de Maresia. Liberta de métricas e rimas, sua obra foi recepcionado com calorosos elogios pela crítica estadual, nacional e internacional, colocando-a em destaque no campo literário. (D’OLIVEIRA, Edy-Lamar. 2008). Agradeço a Sylvia Helena por permitir fotocopiar o exemplar, boneco do livro, presenteado por Edy-Lamar, antes de se tornar conhecimento público.

${ }^{13}$ Esteira de fibra, palha.

${ }^{14}$ Canoa pequena e esguia.
} 
$\mathrm{Na}$ perspectiva da infância enquanto inspiração e o "Marajó" como missão, configurações elaboradas por Sylvia Helena tracejam outros enredos da vida na região, especialmente ligadas às fazendas e áreas de pesca. Desse modo, seus romances dão conta de reconstituir a difícil vivência de indígenas, negros, afroindígenas em suas relações com fazendeiros e capangas da região, assim como práticas de sociabilidades e ódios que, ao despontarem entre fazendeiros, enredavam todos seus empregados, tornando os arraiais de festas religiosas, barril de pólvora, pronto a explodir em brigas e gerar assassinatos. Origens desses rancores remontavam há séculos, afirma Tocantins, conservados pelos antepassados e transmitidos adiante pelas futuras gerações. Alguns fazendeiros marajoaras eram oriundos do nordeste brasileiro e ali desenvolveram rivalidades, fosse do ponto de vista de negociatas mal resolvidas, ou por causa de complicadas relações amorosas. Quando migravam para suas novas propriedades, traziam consigo seus dissabores, renovando-os nos campos marajoaras.

Proveniente da aristocracia da região, a sensibilidade da contista e romancista fez valorizar, em sua composição literária, táticas da cultura popular e jogos de poder nas estratégias das elites latifundiárias na foz do rio-mar (CERTEAU, 1994). Tocantins revive pelejas entre linguagens de tradições orais e eruditas, crenças e saberes imbricam-se nas ações dos variados personagens. D’Oliveira (2008), comentando sobre As ruínas de Suruanã, assinalou: "se impõe como documento de informação folclórica e étnica, relatando (...) os costumes, as crendices, rezas e cantigas, a miscigenação, além de abordar com perfeito domínio as questões: da impunidade, do roubo de gado, do abuso de poder, a invasão de limites, os desmandos em geral".

A maneira de compreender o mundo mítico-fantástico, marca profunda da identidade cultural marajoara, em Sylvia Helena emerge com outros tons. Seus escritos sinalizam um cenário primitivo, de uma gente que enfrenta, cotidianamente, "rigorosas invernadas de pé no chão e chapéu de palha". Sabem conviver com o causticante verão, a terra rachada de onde brotam o juquiri espinhento, pois estão "sempre de bom humor", habilidosamente encontrando remédio pra todos os tipos de desesperanças a bater em sua porta. Nessa batalha desigual, silenciosa, Tocantins afirma ser o marajoara "um herói anônimo, na luta do ganhapão" (TOCANTINS, 1987, p. 14).

No campo das religiosidades, a romancista assinalou que o marajoara é de uma credulidade máxima, capaz de ultrapassar a racionalidade cartesiana e atinge o sobrenatural. "Vive o nativo da ilha, num labirinto fascinante de lendas e 'causos', campos e cerrados, planícies e igapós. Conserva a crendice das gerações antecedentes, fiéis às suas origens 
indígenas" (TOCANTINS, 1987, p. 14). Nesse universo, lido como lento tal e qual o "giro vagaroso dos carros de boi", desvela-se o mundo dos caruanas ${ }^{15}$, expressando fusões entre linguagens e potencialidades de culturas sonoras afroindígenas. "Quando a noite invade o espaço, há um toque de mistério sobre as palhas miserandas dos tejuparés ${ }^{16}$, na hora em que sopra a fumaça da mucurana ${ }^{17}$, vinda dos congares dos pajés, dentro da brenha cerrada. E no silêncio das horas perdidas ronca o tambor do carimbó, num ritmo sensual, contagiante, envolvente, cadenciado" (TOCANTINS, 1987, p. 14).

Sempre inspirada em suas lembranças de infância, quando traduz a vida na região, Helena Tocantins construiu uma tipificação do marajoara de verve submissa e respeitadora décadas atrás, muito inclinado a instrumentos de culturas sonoras multiétnicas, com mudanças em seu comportamento presente. "O caboclo que eu conheci quando criança tomava a benção até das patroinhas, usava chapéu de carnaúba debruado, faca na bainha, baeta vermelha de flanela durante as invernadas, tocava violão, flauta, banjo, cavaquinho, tambor. Hoje trocou a viola pelo radinho de pilha, a baeta pela capa de plástico, o chapéu pelo boné, já usa termos de gíria, da cidade grande" (TOCANTINS, 2005, p. 12).

Para a escritora, essa mudança joga à penumbra a beleza do passado marajoara. Traços culturais como "a ingenuidade do caboclo, o encanto roceiro, o linguajar peculiar, o sistema de crenças em encantarias, visagens, assombrações", estão sendo consumidos e destruídos pela lógica do progresso em expansão como "punha de dois grumes, constrói e destrói ao mesmo tempo". Nessas considerações, Helena Tocantins deixa entrever cuidados com a conservação das tradições que caem em desuso, sem mais evidenciar astúcias do popular marajoara para resistir às avassaladoras entradas de meios e equipamentos de mundos urbanocêntricos.

Na próxima parte deste texto, a partir de mergulhos nos romances As Ruínas de Suruanã e A Lenda do Amor Eterno, de Sylvia Helena Tocantins, rastrearemos indícios da presença, das lutas, das táticas e dos saberes e fazeres de indígenas e africanas na Amazônia Marajoara. Procuraremos evidenciar como outras linguagens comunicacionais, como a Literatura Regional, tornaram-se canais por onde populações de tradições orais sabiamente permitiram aos romancistas inscreveram suas identidades e trajetórias. A persistência de saberes dessas culturas registradas em obras literárias trazendo narrativas orais, cantigas,

\footnotetext{
${ }^{15}$ Entidades das matas e das águas que compõem o mundo da encantaria amazônica. Ver desdobramentos no VII capítulo deste trabalho.

${ }^{16}$ Espécie de palha utilizada na coberta de habitações marajoaras, especialmente de camadas de menor poder aquisitivo.

${ }^{17}$ Árvore sagrada de onde se extrai sementes para os rituais de defumação e incorporação em rituais da floresta.
} 
chulas, rezas e benzeções, ajudam a questionar a invisibilidade do trabalho com a história e cultura indígena e africana em espaços brasileiros e amazônicos. A perspectiva é abrir, então, discussões com pesquisadores para que possam valorizar, em seus cotidianos de estudo e trabalho, experiências sociais de diferentes tradições de oralidades que se esparramaram pelo Brasil, construindo caminhos para pensares inovadores que procurem inserir no currículo escolar a temática das histórias, culturas, identidades e memórias indígenas, africanas, afroindígenas e de comunidades afrodescendentes da região.

\section{Lutas de Negros e Saberes Afroindígenas}

Em A Lenda do Amor Eterno, Sylvia Helena Tocantins traz a história do velho Damião, professor de cartilha dos filhos dos vaqueiros, que desfiou de sua memória a ancestral lembrança:- "Certa vez, murreu um curuné qui tinha fama de viulento e perverso, isso no tempo da escravidão condo havia munto negro nu Marajó, de deferentes raça e condo era custume os branco abri a ferro e fogo o nome do amo nu peito du escravo fujão". Como espetáculo de contação de história onde todos participavam, Januário cortou: - "Cruz, credo! Nem qui fussem bui. E sarava cum que? - Cum sar e copaíba, respondeu Damião. - Diacho era quem quiria nasce nesse tempo mardito, mas cunte o resto, imendou Polidório traçando uma jiribana $^{18 ",}$ (TOCANTINS, 2005, 72).

A história prosseguiu sobre um clima de atenção, medo e benzeções, em intensa intervenção de todos. Narrou Damião que o maldoso coronel mandou construir um poço bem fundo que se comunicava por um túnel com o rio ou igarapé onde havia muitas piranhas. $\mathrm{O}$ negro fujão que caísse ali desaparecia sob os dentes afiados daqueles terríveis peixes. Era o maior castigo para filhos das Áfricas. O lugar passou, então, a ser de assombração. "As hora morta da nuite, gente churava e gimia lá no fundo". No dia da morte do coronel, no salão de sua casa, enquanto seus parentes lhe faziam quarto, em volta do caixão saiu de dentro uma língua de fogo que esfumaçava e deixou o ambiente fedendo a enxofre. A chama escapuliu pela janela e o caixão ficou vazio. Por fim, quando foram enterrar o caixão, tinha dentro um tronco de árvore seco e todo ruído de verme.

Pelas veias dessa narrativa, acompanha-se trânsitos e injunções de produtos (salafricano/copaíba-indígena) e entidades (diabo-catolicismo/língua de fogo-rituais afros) de realidades compósitas, assim como imaginários afroindígenas e sutis resistências frente a sinais da persistente escravidão, que teima em se atualizar, nos anos de 1940 e ainda hoje, em

\footnotetext{
18 Jiribana: corda de relho.
} 
lutas pelo reconhecimento de espaços de habitação para quilombolas, conforme reivindicações de mulheres aquilombadas de Salvaterra, apreendidas em pesquisa de Marin (2006) ou comunidades rurais de Gurupá, que assumiram a defesa de suas identidades negras. O contar desses episódios por negros e afroindígenas, conecta-se a outras artimanhas dessas culturas de expressões orais alimentadas com batucadas, cantorias de chulas, danças, no contínuo almejar de horizontes de liberdade e cidadania. As narrativas das mulheres quilombolas de Salvaterra trazem à tona memórias de lutas, experiências, sofrimentos, rebeldias que desestabilizam controles e poderes oficiais. Ao reivindicarem caminhos de vida, rearticulam tradições de embates contra a escravidão empreendida no passado por comunidades de fugitivos, seus ancestrais (GOMES, 1999; 2005), colocando-as à luz de enfrentamentos e reorganizações do presente. Os tempos de conflitos parecem nutrir-se dos fios de memórias não rompidos pelos poderes dominantes, indicando que ainda persistem clamores por liberdade em reinvenções cotidianas (POLLAK, 1989; 1992).

Nesses universos de complexas experiências sociais, poderes e saberes locais, enriquecidos em trocas culturais, recorrer a práticas de cura, utilizando diferentes ervas, orações sob prescrições de curandeiros, ainda hoje constituem, em povoados amazônicos e marajoaras, saída encontrada por homens e mulheres para livrarem-se de doenças e malinezas. O uso da nativa andiroba, rebuçada de gengibre da África para tosse; chá de arruda africana com vinho de mesa oriundo da península ibérica para evitar gravidez; folha de jucá e azeite de copaíba nativa para estancar sangramento; chá da folha de canarana para dor de urina; banha da capivara e sebo de carneiro da África para curar dores nas juntas; mamona africana e andiroba nativa para eliminar quirana ${ }^{19}$ da cabeça; usar bentinho indígena no pescoço e defumar a casa com breu para espantar os maus espíritos, em espécie de ritual afro, assim como no portão da casa plantar o "comigo ninguém pode", para afastar os invejosos e os quebrantos; tomar leite de jaracatiá para anemia; colocar ninho de cauré para trazer saúde e paz ao lugar onde se reside, são evidentes sinais, não apenas de equilíbrios cultura e natureza, como de africanos e seus descendentes com nativos, no uso de saberes tradicionais da floresta, no seio da cultura marajoara. Essas práticas de cura, ainda hoje vivas na Amazônia Marajoara, reatualizam-se no seio de famílias rurais que, ao migrarem para o espaço urbano, não perderam sensibilidades e relações com sabedorias da medicina da terra e das águas.

A prática de aparar crianças por velhas parteiras como Mãe-Sabá, personagem do $A$ Lenda do Amor Eterno, por exemplo, era valorizada por todas as famílias das fazendas. Da

\footnotetext{
${ }^{19}$ Semelhante a caspa ou seborréia.
} 
senhora da casa-grande até as mais pobres negras do rancho, a confiança nessas parteiras dispensava a medicina científica, mesmo depois da chegada dos postos médicos e unidades básicas de saúde, nos nascentes espaços urbanos, próximo as fazendas. Rodeada de essências aromáticas e ervas medicinais, que ganhavam maiores poderes com orações específicas para mulheres em tempo de partejamento, as habitações entravam num clima de expectativa à espera da nova criança que estava por vir. Os segredos dessa prática eram mantidos a sete chaves. Para crianças e adolescentes, outras explicações eram elaboradas, pois os valores daquele tempo não permitiam a construção de um diálogo aberto e horizontal nas relações pais e filhos.

O trato antes e depois do parto, compunha-se de atitudes de muitos cuidados, com a parturiente e o recém-nascido. Não falar determinadas expressões, tabus alimentares, orientações para o uso de alguns objetos, a proteção do tempo, tornavam a quarentena um período de resguarde e descanso total. "Num fale em morte perto do berço, meu fio. As paredes tem uvido e os anjo diz, amém" (TOCANTINS, 2005, p. 53), chamou atenção de ZéTolentino, Mãe-Sabá. Prescrições, por exemplo, da velha negra e parteira para que a parturiente não dormisse no escuro com o recém-nascido, até que fosse batizado ou não estender sua roupa à luz da lua, precavendo dores, outras doenças e até mesmo a morte (TOCANTINS, 2005, p. 36), sem esquecer de queimar o nó do umbigo no fogareiro de barro para chamar a sorte. E ainda, para ter boa memória, bastava dar para a criança miolo de japiim, recompõe esse universo de valores, princípios e comportamentos locais.

As fortes ligações com mundos visíveis e invisíveis de tradições indígenas, africanas nas simbioses afroindígenas, expressam entendimentos de códigos de comunicação com o dito sobrenatural ou seus duplos em sua relação com a realidade vivente (HAMPATÉ BÂ, 2011). Maria Rita sofrendo de comichão nos olhos, apegava-se com Santa Luzia, encantados e orixás. Sobre essa bricolagem de religiosidades, questionou Januária, também personagem do romance A lenda do Amor Eterno: "Tombem tem acendido munta cera, só acho isturde as cera sê vermeia, paresque cera di pajé. Quem faz rogo pra Santo num frequenta kongá de fiticero". O uso, por exemplo, de colar com dente de jacaré para espantar mal olhado ou ruindezas do mundo, difere dos tipos de jóias valorizados pela cultura ocidental urbana. Conflitos de valores em torno dessa questão são evidenciados em Tocantins. Angelina, filha do rico coronel da fazenda Estrela D'Alva, questionou porque Zé-Tolentino filho, usava aquele esquisito adereço. Pelo forte sentimento que a unia ao negro e capataz da fazenda, prometeu presentear-lhe com um cordão de ouro. Francisca, mãe de Zé-Tolentino, criada da fazenda, por sua vez, carregada de saberes da tradicional medicina popular e curativa da 
região, quando encontrava Angelina, tomada pelo febrão e caída de mofineza, exclamava: "É quebranto, meu fio, tá a modo molenga, suando frio, vá depressa chama a veia Engrácia, no Rancho".

Neste romance, Helena Tocantins ainda recupera do imaginário marajoara histórias de bois misteriosos a desafiar habilidosos vaqueiros, cujo cenário envolve o rio, a cobra grande e os poderes da medicina popular sob a mediação de médicos da floresta. Nessa narratividade, esboçam-se novos elementos da complexidade que envolve o ser marajoara, em suas relações com o meio circundante e suas potentes forças cósmicas (ANTONACCI, 2005). "Contavam que um boi misterioso desafiava o vaqueiro mais destemido e quando laçado corria para o rio e entrava n'água, mergulhando. Então a corda partia-se e no dia seguinte encontravam o resto da corda enrolada na margem transformada numa cobra grande. Dava um febrão no vaqueiro que só o pajé o salvava com rezas e puçangas” (TOCANTINS, 2005, p. 42).

Em A Lenda do Amor Eterno, apreendemos sentimentos de aversões entre grandes coronéis dos campos com a intendência municipal belemita, na pessoa do ícone da Belle Époque paraense, Antônio José de Lemos. Neste romance, conforme D’Oliveira (2008, p. 114), Tocantins, com a autoridade de quem viveu a realidade marajoara, rasgou véus de verdades encobertas por preconceitos, diferenças sociais, raciais e culturais. Pintando "a rotina das fazendas e dos agregados, as diversas manifestações folclóricas que acompanham os ritos e os mitos locais, a preocupação com a linguagem nativa fielmente reconstituída, os costumes, a miscigenação, as diferenças de classes e de raças em todas as suas nuances e as realidades duras dessas vidas que se mesclam e se desintegram como simples objetos de material perecível, sob a força imponderável das águas do destino".

Para tanto, outras narrativas e manifestações locais tonalizam experiências populares, retratando rituais e práticas culturais em meio a sociabilidades e conflitos. Rica de detalhes da cultura material e sensível de povos oriundos de "zonas de contato" 20 entre vivências africanas, indígenas e europeias, a literatura de Sylvia Helena Tocantins revela-se fonte indispensável para quem pretende percorrer e compreender emaranhados de tensas e dinâmicas relações sociais enlaçadas na história da região marajoara.

Sintonizada nesses horizontes de entrelaçados saberes e crenças, em As ruínas de Suruanã, Tocantins esculpiu a performance da linda jovem mulata Minervina, - faceira,

\footnotetext{
${ }^{20}$ A expressão "zonas de contatos" foi pensada por (PRATT, 1999, p. 27), para dar conta de "espaços sociais onde culturas díspares se encontram, se chocam, se entrelaçam uma com a outra, frequentemente em relações extremamente assimétricas de dominação e subordinação - como o colonialismo, o escravismo, ou seus sucedâneos ora praticados em todo o mundo".
} 
petulante, rebolativa, vista sempre recendendo a ervas aromáticas e com uma infinidade de berenguendens em seu corpo -, com heranças de seus antepassados que a colocavam em posição de cobiça masculina no Marajó dos Campos. Dotada de diferentes ofícios, - como lavadeira e engomadeira, rezadeira de quebranto, espinhela caída, erisipela, mãe do corpo; conhecedora de artes culinárias e outros artifícios, fazia beijus, garrafadas milagrosas, banhos de cheiros utilizando cravo, alecrim, canela e manjericão -, Minervina enlaça elementos de identidades afroindígenas, tão vivos na região, que Sylvia Helena Tocantins fez questão de recuperar em sua prosa poética.

Recorrendo a dois estilos de linguagem - o caipira e o erudito -, para montar o enredo de conflituosas relações entre o bem e o mal, na amaldiçoada fazenda de Suruanã, Helena Tocantins pintou um retrato do complexo cotidiano das fazendas. O viver nesses espaços distingue-se de outras regiões, à medida que expressões dos modos de ser dos personagens, como histórias e contos, crenças e cantos de chulas, por exemplo, são apresentados. Filha de fazendeiro, a poetisa, contista e romancista nuança seus escritos com a rica linguagem "cabocla", deixando seus leitores cum subrussu ${ }^{21}$ pelas dificuldades que a racionalidade impôs à formação acadêmica.

Neste romance, inspirando-se, em linguajar socialmente vivido em campos marajoaras, a literata articula um enredo em que a trama, traz histórias imbricadas entre cinco personagens centrais. A "mulata" Minervina, o negro fazedor e tocador de chula da fazenda, Mané Coquinho, cuja musa inspiradora é protagonista da história, o delegado de polícia por quem Minervina se apaixona e engravida, o coronel Vilaça e seu malvado capataz Agripino, que tramam a morte do delegado para que o coronel possa conquistar a mulata. Para esmiuçar com maestria e marcar a verve de sua tragédia romanesca, Tocantins apresenta logo de início formas de comunicabilidade bem distintas: o falar popular, desenrolado da cabeça de Timóteo e o falar culto e formal, expresso por Leonardo, representante da vida urbana. Este, ao chegar à palhoça de Timóteo, interessado em comprar a fazenda Suruanã, manifestou percepção folclórica daquele lugar que produzia "tardes poéticas"22.

O afroindígena Timóteo constituído e ainda mergulhado nesse universo de tradições, costumes e crenças que, para a cultura erudita, torna-se, quase sempre, objeto de mera contemplação e romantização, dialoga com o branco Leonardo, alicerçado em sua cosmovisão

\footnotetext{
${ }^{21}$ Assustados.

22 "No Marajó tudo me fascina. A crendice do povo, as lendas, a paisagem exótica, selvagem, a beleza crua da natureza, os costumes indígenas, as tradições, enfim, esse conjunto de fauna e flora, esse mistério aquático dos rios e igarapés, essa imensidão de campos verdes, os palmeirais, os pássaros canoros, os animais, as plantas, as muquecas, o arroz de marreco, o açaí, o tucumã, o inajá, até mesmo os aguaceiros - Arrematou com empolgação". (TOCANTINS, 1987, p. 27).
} 
de um Marajó fantástico, pleno de magias, com poderes e saberes em conexões com realidades transcendentais. "É fala currente qui o branco veio di Belém pra fazê negócio cum a Suruanã, mas já si interu da história dela. (...) A modo qui o muço num acridita memo nu passado di Suruanã, mas juro qui fui verdade verdadera. Meu avu, qui já si fui há munto, sempre ripitia pra nois curumins, jitinhos, im vorta da candea, tudo qui tinha apriciado cum os óio qui a terra havia di cume (TOCANTINS, 1987, p. 19 e 22)”."

Procurando desautorizar esse universo popular e desqualificar a fala de quem viveu a persistência de diferentes histórias oralmente transmitidas e enredando vidas marajoaras, Leonardo expressou-se: "Ouvi uns comentários absurdos, crendices de gente do interior, mas isso não importa, Timóteo, não sou supersticioso - Riu-se o rapaz, um tanto divertido". Plena de códigos linguísticos dessa oralidade que comunica formas de conviver com mundos invisíveis e sensíveis, os falares de Timóteo recompõem imaginários com os quais parte dos marajoaras vivem e interpretam ainda hoje seu mundo. Mesmo que mudanças de valores, inserção de outros suportes comunicacionais nos renascentes ou emergentes espaços urbanos, - que exigem a instalação de uma nova racionalidade -, populações locais mostram suas faces impregnadas por símbolos afroindígenas. “- Inté aí tudo bem, tudo certo, meu branco, mas o principar num lhi disserum, qui lá acuntece umas cuisa isquisita, tudus ficum a modo cum subrussu. Vusmicê tem tutiço di i mais eu nu lugá onde fui a Casa-Grande? A Capela? $\mathrm{Nu}$ tronco ondi chora o mininu qui murreu sem batismo? (TOCANTINS, 1987, p. 20)".

Para entrar na fazenda em ruínas e enfrentar as maldições ali derramadas, o afroindígena confeccionou um rosário de caroços do açaí, composto de "cinquenta e três AveMaria, seis Pade Nosso, uma Sarve Rainha e um Credu, murtipricado pur três" (TOCANTINS, 1987, p. 25), ainda que questionada a valia pelo branco, seguiu caminhada para dentro da mata, a fim de alcançar o lugarejo desejado. Aquelas matas escondiam a triste tragédia ocorrida com Minervina, a mulata que encantou com sua beleza e essências, os campos de Marajó. "Quem conheceu Minervina nunca isqueceu dela. Era filha di uma nega cum patrão branco, gente das Oropas, meu avu cuntava. A nega era filha di uma escrava du fazendeiro e munto bunita. Entonces Minervina nasceu um pecado de buniteza, mulata e torradinha cumo burra di café. Tinha os óio di iara incantada, cô di limo nas águas" (TOCANTINS, 1987, p. 30).

Expressando o jeito de ser do homem marajoara, que vive entre campos e mares, Timóteo desfiou de sua memória sinais da tragédia ocorrido em Suruanã, narrando o triste fim de Minervina e seu rebento a partir do desequilíbrio entre forças materiais e espirituais viventes na região. O enredo de As ruínas de Suruanã, conta a triste sina de Minervina, "a 
mulata mais perequeté qui o oiá dus homi já viu”, que engravidou de um jovem delegado, assassinado pelo capanga do poderoso e malvado coronel Vilaça, "peste de ruim qui nem fígado di buto, qui nem urubu comi”. Grávida e assediada pelo coronel, com a proposta de que assumiria a paternidade se casasse com ele, a mulata fez-se sua esposa, para não ficar malvista no povoado. Assinou, contudo, a sentença de sua desgraça, por não suportar o terrível assassinato de seu curumim.

Essas passagens de Tocantins permitem leituras de mundos afro, indígena e católico em grandes misturas. Incorporando elementos da floresta marajoara, populações locais improvisaram suportes universais de simbologias católicas, ressignificando-lhes o uso. O terço feito de sementes de açaí, serve para espantar mau-olhado, assombrações e almas em perdição que circulam entre rios, terras e florestas, sinalizando enredamentos múltiplos em mãos a rezar e solicitar alívios de seus tormentos ao catolicismo popular. Nesses jogos de linguagens, estratégias de vida são apreendidas, fazendo do romance uma obra aberta e em diálogo com outras narrativas e literaturas.

Ampliando horizontes da presença de manifestações africanas no Marajó dos Campos, chulas cantadas pelo negro da fazenda Suruanã, Mane-Coquinho, personagem do romance de Helena Tocantins, reatualizam práticas de festivas culturas marajoaras, que resistem às ameaças e vigilâncias para calar a voz diante do poderoso e cruel coronel Vilaça.

Esse prefume envurvente/ Di cravu, majericão,/ a modo qui dexa a gente/ firidu nu curação. E tu inda disque vem vindo,/ O chero chega premero,/ meu curaçao vai sintindo/ qui tu já vem, pelo chero. É banho di garrafada?/ Jasmim, oriza, canela?/ Qui ti faz tão prefumada/ Cum frevura di panela? Tenho uma discunfiança/ Qui num é banho di lata,/ É tu que desde criança/ Trouxe este chero, mulata! (TOCANTINS, 1987, p. 86)

Permitindo sentir injunções oral/letrado, cultura/natureza, Marajós/Áfricas, mundo indígena e africano, chulas desenroladas da cabeça deste negro, em meio ao ardil cotidiano das fazendas de gado no Marajó dos Campos, permitem alcançar horizontes de sabedorias populares. Reinventadas a partir das novas relações, em constituição nesses ambientes de trabalho e moradia, constroem artimanhas para viver e reafirmar identidades culturais afroindígenas, na contramão de poderes vigilantes. Essas linguagens históricas também se constituíram em canais de contestações contra modos de vigiar e punir populações locais assentadas em seus índices de transmissão oral (FOUCAULT, 1999). Em meio às chulas enquanto cantos de liberdade e de crítica social, híbridas orações fortes também foram recompostas no veio da literatura marajoara como linguagens reveladoras de sabedorias para enfrentar enfermidades. 
Quebranto ou mau oiado/ quem ti trouxe lá do fundo/ que ti leve, ex-comungado/ pra dentro du mar profundo/ qui ti prenda numa concha/ ou ti interre bem nu chão,/ qui nunca di lá tu ti sorte/ pra prisigui este irmão". E depois de outro sinal da cruz, agora no peito, tornou: "Cum nó di fita sagrada/ Du artá da Virge Maria,/ Te amarro inveja danada/ Seja nuite, seja dia./ Amarro o quebranto tombem/ Pade, Filho, Sprito Santo Amém" (TOCANTINS, 1987, p. 76-77).

Rezas para curar malinezas, como práticas que relacionam mundos visíveis e invisíveis em vozes fluentes e rimadas da mulata Minervina, conduzem a sensíveis culturas vocais que desconhecem apartações entre códigos de religiosidades ibéricas e experiências em cosmologias afroindígenas. Nesse entremeio, outros códigos de convivências de universos nativo e em diáspora, misturados ao do catolicismo ibérico emergem das escrituras literárias.

\section{3. Conclusão}

Com base nas informações reunidas e trabalhadas acerca da vida e obra de Sylvia Helena Tocantins, fundamentados na historiografia brasileira e amazônica e nos PósColoniais e Decoloniais, tentamos realizar uma prática de desobediência epistêmica (MIGNOLO, 2010) para captar pontos de conexão entre história e literatura por meio de sinais da presença, das lutas, saberes e fazeres de culturas indígenas e africanas na Amazônia Marajoara. Depois da obrigatoriedade de incluir no currículo escolar a temática História e Cultura Afro-brasileira e Africana por recomendação da Lei 10.639/2003 e da História e Cultura Indígena por recomendação da Lei 11.645/08 (BRASIL/MEC, 2013), faz-se necessário problematizar essencialismos étnicos e visões esteriotipadas que orientam os sistematizas arbitrários de classificação das populações brasileiras e amazônicas.

A contribuição do indígena e do negro para a formação das identidades marajoaras, quando foram noticiadas por viajantes e escritores, estiveram carregadas de preconceitos e olhares folclorizadores. Luxardo (1977, p. 43) ao falar do negro, por exemplo, assinalou: "Do negro, trouxe a doce subserviência, a alegria para os folguedos, o instinto sexual permanente".

Questionar olhares elaborados, dados numéricos apresentados e buscar outras evidências históricas apontariam ricos caminhos para desencobrir trajetórias e apagamentos da presença indígena e negra na Amazônia Marajoara. Desvelar mundos e saberes indígenas aqui existentes e africanos que aqui chegaram, sinais de suas culturas presentes em jeitos de ser e viver da região, são parte de agendas públicas emergentes. Como focar outras marcas de suas matrizes de oralidade, ainda hoje vivas nas manifestações populares e modos de vida locais? 
Por meio dessas três questões, é possível dizer que, para ultrapassar barreiras do racismo e ter condições de formular outras indagações, torna-se necessário aguçar sensibilidades, dilatar a retina do olhar para enxergar o débito social construído com povos indígenas, africanos, afroindígenas, afrodescendentes, quilombolas, muitos deles populações tradicionais de espaços rurais, moradores urbanos de centros e bordas de nossas "cidadesflorestas" e campos marajoaras. Como trabalhar e fazer vivenciar a autoestima dessas populações, geralmente empobrecidas e esquecidas pelas políticas públicas? Que travessias urdir para estabelecer permanentes diálogos com nossas alteridades sem negar ou encolher cosmovisões, expectativas e interesses de homens e mulheres que deram outros tons culturais para campos e florestas marajoaras? De que modo podemos exercitar a equidade nas diversidades em nossos fazeres cotidianos no universo do lar, do trabalho, da religião, do lazer?

Para dar conta de entendimentos parciais dessas questões, neste texto procuramos desvendar e visibilizar saberes, fazeres, crenças, costumes, tradições e formas de luta de populações de tradições orais historicamente invisibilizadas ou esteriotipadas pelo poder das escritas colonialistas. Ciente das especificidades e fronteiras porosas existentes entre os campos da literatura e da história, a comunicação procurou cotejada e cruzar a narrativa literária com outras narrativas de cronistas, viajantes, historiadores e antropólogos para apreender sinais da história e cultura indígena, africana e afroindígena na região. Nesses escritos, acompanhamos experiências de homens e mulheres de matrizes indígenas e africanas que se esparramaram, apropriaram-se, ressignificaram e compartilharam afeto e táticas para driblar a colonialidade de seus corpos, cosmovisões e sentidos, implodindo com as estratégias de vigiar e punir impostas pelos donos do poder contra a liberdade de seus modos de ser, viver e estar no mundo (FOUCAULT, 1994). Deste modo, entre os tempos coloniais e os tempos contemporâneos, histórias, trajetórias e imaginários das culturas indígenas e africanas persistiram, resistiram, sofreram baixas e reinventaram-se nas fronteiras amazônicas. Finalmente, as informações reunidas e trabalhadas acerca da vida e obra de Sylvia Helena Tocantins, em simbiose com diferentes outras escritas, permitiram exercitar leituras do afroindigenismo como postura criativa e problematizadora de identidades fixas e a-históricas que, muitas vezes, negam a interculturalidade dos encontros culturais em territórios da diferença colonial.

\section{Referências}


ANTONACCI, Maria Antonieta. Corpos Negros Desafiando Verdades. In: BUENO, Maria Lucia \& CASTRO, Ana Lúcia (org.). Corpo território da cultura. São Paulo: Annablume, 2005, p. 34-65.

ANTONACCI, Maria Antonieta. Tradições de Oralidade, Escritura e Iconografia na Literatura de Folhetos: Nordeste do Brasil, 1890-1940. Projeto História (PUCSP), São Paulo, v. 22, p. 105-138, 2001.

ARRUTI, José Maurício Andion. Agenciamentos Políticos da "Mistura": identificação étnica e segmentação negro-indígena entre os Pankararú e os Xocó. Estudos Afro-Asiáticos, n. 2, p. 215-254, 2001.

CERTEAU, Michel de. A invenção do cotidiano: 1, Artes de fazer. Petrópolis: Vozes, 1994.

BEZERRA NETO, J. M. Escravidão negra no Grão-Pará (sécs. XVIII-XIX). Belém: PakaTatu, 2001.

CHAMBOULEYRON, Rafael. Escravos do Atlântico equatorial: tráfico negreiro para o Estado do Maranhão e Pará (século XVII e início do século XVIII). Revista Brasileira de História, vol. 26, n. 52, p. 79-114, 2006.

ELEUTÉRIO, Maria de Lourdes. Um desafio irrecusável: A contribuição da literatura para os estudos da história. Projeto História, São Paulo, v. 20, abril de 2000, p. 227-236.

FERREIRA, Alexandre Rodrigues. "Notícia Histórica da Ilha de Joanes ou Marajó". Revista do Livro, ano VII, n 26, Instituto Nacional do Livro, Rio de Janeiro, 1964, P. 47-63.

FOUCAULT, Michel. Vigiar e punir: o nascimento da prisão. 20 ed. Tradução Raquel Ramalhete. Petrópolis, Rio de Janeiro: Vozes, 1999.

JURANDIR, Dalcídio. Os viradores de madeira. O Estado do Pará, Belém, junho de 1939.

GALLO, Giovanni. Marajó: a ditadura da água. Belém. 2. ed. Edições “O Nosso Museu. Santa Cruz do Arari, Pará, 1981.

GANDON, Tania Almeida. O índio e o negro: uma relação legendária. Afro-Ásia, n. 19/20, p. 135-164, 1997.

GILROY, Paul. O Atlântico Negro. Modernidade e dupla consciência, São Paulo, Rio de Janeiro, 34/Universidade Cândido Mendes - Centro de Estudos Afro-Asiáticos, 2001.

GOLDMAN, Marcio. A Relação Afroindígena. Cadernos de Campo, São Paulo, n. 23, p. 213-222, 2014

GOMES, Flávio dos Santos. Fronteiras e Mocambos: O protesto negro na Guiana Brasileira. In: GOMES, Flávio dos Santos. Nas terras do Cabo Norte: fronteiras, colonização e escravidão na Guiana Brasileira - séculos XVII/XIX. Belém: Editora Universitária/UFPA, 1999, pp. 237-325. 
GOMES, Flávio dos Santos. A Hidra e os Pântanos: mocambos, quilombos e comunidades de fugitivos no Brasil (sécs. XVII-XIX). São Paulo: Ed. UNESP: Ed. Polis, 2005.

HALL, Stuart. Da Diáspora: identidades e mediações culturais. Belo Horizonte: Editora UFMG; Brasília: Representação da UNESCO no Brasil, 2003.

HAMPATÉ BÂ, A. A tradição viva. In: KI-ZERBO, Joseph (editor) Metodologia e préhistória da África. Tradução MEC - Centro de Estudos Afro-Brasileiros da Universidade Federal de São Carlos. 3. Ed. - São Paulo: Cortez; Brasília: UNESCO, 2011, pp. 167-212. -

LUXARDO, Líbero. Marajó: Terra Anfíbia. Belém: Grafisa, 1977.

MIGNOLO, Walter D. Histórias Locais/Projetos Globais: colonialidade, saberes subalternos e pensamento liminar. Tradução de Solange R. de Oliveira. Belo Horizonte: UFMG, 2003.

MIGNOLO, Walter. Desobediência epistémica: retórica de la modernidade, lógica de la colonialidad y gramática de la descolonialidad. Buenos Aires: Del Signo, 2010.

PEREIRA, Manoel Nunes. Negros escravos na Amazônia. In: X Congresso Brasileiro de Geografia realizado na cidade do Rio de Janeiro (D.F), de 07 a 16 de setembro de 1944. Vol. III. Rio de Janeiro: Conselho Nacional de Geografia, 1952, p. 153-185.

PRATT, Mary Louise. Os olhos do Império: relatos de viagem e transculturação. Bauru, SP: EDUSC, 1999.

POLLAK, Michael. "Memória e Identidade Social”. Estudos Históricos, Rio de Janeiro, v. 05, n. 10, p. 200-212, 1992

POLLAK, Michel. "Memória, esquecimento, silêncio". Estudos Históricos, Rio de Janeiro, v. 02, n. 03, p. 03-15, 1989.

SALLES, Vicente. O negro no Pará sob o regime da escravidão. Rio de Janeiro: FGV; Belém: UFPA, 1973.

SANTOS, Boaventura de Sousa. Pela mão de Alice: o social e o político na pós-modernidade. 6. ed. São Paulo: Cortez, 2001.

SANTOS, Eufrázia Cristina Menezes. O Atlântico Negro (Resenha). Revista de Antropologia, São Paulo, USP, V. 45, nº 1, p. 273-278, 2002.

SCHWARTZ, Stuart B. Tapanhuns, Negros da Terra e Curibocas: causas comuns e confrontos entre negros e indígenas. Afro-Ásia, n. 29/30, p. 13-40, 2003.

III. TOCANTINS, Sylvia Helena. A Lenda do Amor Eterno: romance marajoara. Belém: IOEPA, 2005.

TOCANTINS, Sylvia Helena. As ruínas de Suruanã: romance marajoara. Belém: Gráfica Falangola, 1987. 
IV. TOCANTINS, Sylvia Helena. No tronco da Sapopema: vivências interioranas (Vigia e Marajó). Belém: IOEPA, 1998.

VERGULINO-HENRY, Anaíza \& FIGUEIREDO, Arthur Napoleão. A presença Africana na Amazônia Colonial. Uma notícia histórica. Belém: Arquivo Público do Pará, 1990. 